\title{
The Great Equalizer? Gender, Parenting, and Scholarly Productivity during the Global Pandemic
}

Marijke Breuning, University of North Texas

Christina Fattore, West Virginia University

Jennifer Ramos, Loyola Marymount University

Jamie Scalera, Georgia Southern University

\section{Introduction}

Has the global COVID-19 pandemic negatively impacted the scholarly productivity of academics? Do gender and parenting magnify its effect? There is a widespread perception in the popular media, as well as in publications on higher education, that women - especially those with small children - have seen their time diverted to caregiving duties (Malisch et al 2020; Matthews 2020; Miller 2020; Minello 2020; Windsor and Crawford 2020a). If these perceptions prove true, the pandemic's disruptions could have a long-lasting negative impact on progress for women in academia as individuals and as a group (Stack 2004).

Understanding the gendered impact of the pandemic is important: women have made progress in academia, but their proportion of the professoriate remains lower than their share of PhDs earned (National Science Foundation 2019; APSA 2020; Windsor and Crawford 2020b). Although men now more often perceive themselves as active parents, which suggests they may also sense a negative impact on their productivity as scholars, a recent survey shows that women are still doing the bulk of carework during the pandemic (Miller 2020). 
We investigate how women and men, both those who are and are not parents, perceive the pandemic's impact on their scholarly productivity. This early evaluation provides insights that may facilitate effective responses to safeguard the professional advancement of women. To obtain insight into the changes the pandemic has wrought to lives and careers, we surveyed scholars in political science and international studies. The survey was fielded May 2020, while

many academics experienced shelter-at-home orders and were adjusting to a new reality. Hence, the survey captures initial reactions to changed circumstances, as well as the fears and anticipated consequences of the disruptions. We find that substantial proportions of all respondents perceive a negative impact of the pandemic on their productivity and for the status of women. A review of the open-ended responses suggests the pandemic may reinforce, and possibly widen, a parent productivity gap.

\section{Background}

Early reports suggest that the pandemic has exacerbated existing disparities among academics (Malisch et al 2020; Matthews 2020; Miller 2020; Minello 2020; Windsor and Crawford 2020a). Hence, women and parents run the risk of losing ground. Fattore (2018) shows that the status of women has improved, but also that much work remains to be done.

Previous surveys show that both women and men report that academic careers negatively impact their personal lives, including the choice to have fewer children and a variety of stressors that affect their home lives (Fattore 2018; Hancock et al 2013). Hancock et al (2013) show that women more often reported that their children spend significant time in the care of others. They concluded that women often depended on such care in order to balance work and life (Hancock 
et al 2013; Schiebinger and Gilmartin 2010). That conclusion is supported by research that demonstrated that women with young children published less than others (Stack 2004).

This suggests that shelter-at-home orders - and the accompanying absence of childcare and closures of schools - quite likely affect women and men in different ways. Parents, in particular, face significant disruptions as they attempt to remain productive while also serving as full-time caregivers (and, in many instances, educators) for their children (Minello 2020; Windsor and Crawford 2020a). The pandemic has changed the routines of almost everyone, but not equally. For instance, there is some early evidence to suggest that male scholars are submitting to academic journals at rates higher than prior to the pandemic and female scholars at lesser rates (Flaherty 2020; Malisch et al 2020; Kitchener 2020; Viglione 2020).

This literature, as well as early anecdotal evidence, suggests that the global pandemic is quite likely to influence scholarly productivity during this period and in the months, and possibly years, to come. Hence, we anticipate that female scholars, especially those who are parents, are highly likely to report that their productivity has declined during the pandemic. The impact on men is less clear: the literature and early evidence suggest that they may be more productive. However, men who have more active parenting responsibilities might also experience a decline in productivity.

\section{Data and Methods}

To systematically evaluate changes in scholarly productivity as a result of the global pandemic, our team fielded a survey of scholars in the discipline, between May 6-30, 2020, after obtaining IRB clearance. Respondents were recruited via emails to the members of the International 
Studies Association, as well as through the team's social media. While the sample is nonrandom and oversamples women, it captures a broad cross-section of scholars in the discipline.

The survey yielded 1003 respondents overall. Our analysis focuses on the sample that includes 655 female and 338 male respondents. The respondents include scholars of all ranks from graduate students to retired faculty. Almost $60 \%$ of the respondents are based in the United States (US), with rest based in a variety of locations around the globe. We include all respondents here. The results would be substantially similar had we selected only US respondents, except the sample would have been smaller (see Appendix B).

Our sample included 386 respondents who indicated that they are parents to children under eighteen years of age who are living at home. Of these, 239 (or 62\%) are women and 147 (or 38\%) men. In most cases, the children are living with the respondent full-time. This was the case for all but three respondents, all men. In addition, 28 women and 10 men are parenting without a spouse or partner. This means that only $12 \%$ of the female and $7 \%$ of the male parents in the sample are parenting solo. Although this category is represented by a very small number of respondents, we include it in our reporting because the effect of balancing caregiving and productivity during the pandemic might be amplified for those parenting solo.

To evaluate the impact of the pandemic on scholarly productivity, we asked respondents to indicate their agreement or disagreement with several statements. The full scale included the following options: strongly disagree, disagree, neither agree nor disagree, agree, strongly agree, and not applicable. We excluded the last response from our analyses and recoded the scales to combine 'strongly disagree' and 'disagree,' as well as combine 'strongly agree' and 'agree,' to yield a three point scale: (strongly) disagree, neither agree nor disagree, (strongly) agree. 
In addition, we draw on the open-ended responses, of which there were 238 total received in the survey. We collected 47 responses based on the following search terms: parent (10 responses), caregiving (9 responses), child (25 responses), and kid (3 responses). Some of the responses were duplicates across the search terms, and some of the responses were from selfidentified parents while others were from non-parents who were commenting on their perceptions of the circumstances facing parents or caregivers broadly. The respondents who took the time to provide these detailed answers provide insight into the pandemic's toll on the productivity of especially women and parents.

\section{Perceptions of Productivity}

\section{Descriptive Statistics}

Counter to what the literature suggests, we found that women and men responded in very similar ways to the statements regarding a decline in their personal productivity as a result of the global pandemic, both now and into the future. We asked respondents to rate their agreement or disagreement with the statement: "I am unable to write/research at home in a way similar to my productivity prior to March 2020." This is reported as statement one in Table 1 and reflects respondents assessment of their productivity in the immediate term. We also asked respondents for a similar rating of the statement: "I worry that my research productivity will decrease significantly because of the COVID-19 pandemic.” This statement indicates respondents' concerns about their productivity into the future; the results are reported as statement two in Table 1. Both questions seek to ascertain the pandemic's perceived effect on scholars' individual productivity. 
The first three columns of Table 1 show the responses of the full sample, the second three columns the responses of parents, and the last three the responses of those parenting solo. The results for the full sample, parents, and parenting solo all look quite similar: for all three, there is very little difference in the responses of women (F) and men (M). All three show the largest proportion agreeing with both statement one and statement two. Thus, both women and men perceive the pandemic as disruptive to their ability to write and conduct research and both worry about their own productivity. The differences between women and men are not statistically significant.

Whereas the previous statements asked respondents about individualized effects of the pandemic, statements three and four are more group-focused, relating to the broader context of academia. Statement three and four ask respondents to assess the implications of the pandemic on caregiving considerations and women's status, respectively. The findings for statement 3 are not as striking, but around half of the respondents (strongly) disagree that: "Post-pandemic, academia will be more considerate concerning the effects of caregiving on scholar productivity." For all groups and the gender category, the distribution between the response categories is flatter than for statements one and two. Respondents do not perceive that the current disruption will yield a greater consideration of the impact of caregiving roles on the ability to be productive as a scholar. As mentioned earlier, although women already face structural inequalities, across all groups both women and men agreed that "women will be worse off than men in academia, postpandemic" (reported as statement four in Table 1). Again, there is very little difference between women and men, underscored by the lack of statistical significance.

Our findings (reported in the Appendix A) are similar when we compare parents and nonparents (full sample, women, and men), or focus on those in more vulnerable professional 
positions, e.g. women and men assistant professors or graduate students (all and those who are parents). The size of subsamples is sometimes small, but each exhibits the same trends: both women and men report feeling the negative impact of this pandemic on scholarly productivity.

\section{Patterns in the Open-Ended Responses}

Open-ended responses allow us to look more closely at the concerns of specific groups to flesh out the results borne from the statistical analysis. Here, we are interested in those with caregiving responsibilities for underage children, who we expect to be among the more challenged during the pandemic. Of the 238 open-ended responses in our survey, 47 of them (19.7\%) mentioned childcare and parenting specifically ${ }^{1}$. Further confirming the statistical results, parents are struggling with striking a balance between their work and home lives.

One of the main themes that emerged from the open-ended responses was the difficulty in balancing work-life demands for academics with children. One respondent summed this up by saying, "academic work load has always been difficult to manage and the last couple of months it has been frankly impossible." For respondents, the most time-consuming challenge seems to be providing at-home education for their children. Many cited the challenges of supporting their "kids' learning while also being productive with teaching and research." In fact, some say that supervising their children's distance learning takes "more time than working on my own work."

As a consequence, respondents noted that research productively has been reduced to little to none. Some academic parents fear that their unexpected role as a stay at home caregiver has jeopardized their preparedness to go on the job market or to obtain grants necessary for promotion. Parents are clearly very concerned about their futures, as marked by their language

\footnotetext{
${ }^{1}$ Search terms: "parent", “child", "kid", "caregiving”.
} 
throughout the comments: "draining me," "in near-despair," "really worried," "terrified," "fear my career might be doomed." One scholar writes: "I am terrified I will not be able to produce published research. My department is very firm about their high research standards for tenure (4 articles +1 book) and I doubt they would consider relaxing or changing those standards." These fears also seem to be borne out in the quantitative analysis. Another agrees that the consequences of the pandemic may "permanently push me out of academia."

In terms of gender, 13 of the 47 parent-related comments mentioned that women do and will continue to carry an outsized role for childcare, which will have an adverse effect on their careers. ${ }^{2}$ For example, even with a tenure clock extension, "I worry that as a mother of a young child, my productivity will be disproportionately affected, so it won't matter." While some respondents believe that "men seem to be shirking caregiving duties and have seemed to be more productive," other respondents acknowledged that men are "taking on fully half (if not more) of the homeschooling responsibilities..."

To be sure, several men acknowledge that they are sharing childcare responsibilities and are concerned that "young male faculty may get overlooked." Some note that they are also unsure how to signal these responsibilities on the job-market or in their tenure files. These sentiments confirm the findings of the statistical analysis that reveal all academics who are parents harbor significant concerns.

Still, in terms of gender disparities, several respondents mentioned that the pandemic has only served to highlight, and perhaps reinforce, structural differences between women and men in academia. One writes: "I also think that the bulk of authors in top journals will be men over the next few years, but that was true before the pandemic and is a larger structural issue."

\footnotetext{
${ }^{2}$ Search terms: "mother," “mom," "female," "woman".
} 
Another respondent, who self-identifies as "a chubby, old, eurowhite, cisgendered, heterosexual, vaguely culturally Jewish, atheist, anarcho-syndicalist professor," confirms these fears: "I think academia continues to be structurally \& institutionally male-dominated \& male-oriented and fear current events will make this worse. As the parent of a junior faculty member I see this pretty upclose." As for whether these issues will change, one respondent worries that "the propagation of stereotypes that only women engage in caregiving and that male academics should have seen a productivity boon during the pandemic will further fossilize gender roles and make it harder for male academics to engage in equal parenting and caregiving." Thus, while the challenges of managing the work life balance do seem more severe for women, it is likely that male parents will also suffer significant consequences due to the toxically masculine viewpoint that men should participate minimally in caregiving.

Overall, among parents, ${ }^{3}$ there does appear to be a more general consensus regarding a productivity gap between those with children and those without, which confirms the findings of the statistical analysis. While gender disparities certainly persist, the open-ended comments confirm that the pandemic may reinforce or widen a productivity gap between those with children and those without.

\section{Discussion/Conclusion}

Our main interest was in the effects of the COVID-19 pandemic on the scholarly productivity of academics and, in particular, whether gender and parenting amplified its effects. We employed survey data and open-ended responses to investigate these questions. Overall, our findings point to the negative impact of the pandemic for respondents' research productivity and

\footnotetext{
${ }^{3}$ While we focus on parenting, we recognize that caregiving includes elder care.
} 
for the status of women in the profession. In addition, a review of our open-ended responses suggests a potential parent productivity gap. We summarize these below.

While media reports have emphasized the negative effect of the global pandemic on the productivity of women and parents, especially female parents, our descriptive statistics illustrate remarkable consistency across different groups in their reported inability to write and research, a fear of lost productivity, and little hope that academia will better address the impact of caregiving on productivity post-pandemic. Not surprisingly, most do agree that women will be worse off when the dust settles from the pandemic. Regardless of gender or whether one is a parent, there is a pessimistic outlook across these indicators.

As we turn to the open-ended responses, the story continues to be one filled with worry and distress as scholars struggle try to cope with managing their work and personal lives during the pandemic. Yet, what we see more clearly in the open-ended responses that we did not with the descriptive statistics is the real concern for the way in which the pandemic has put a massive strain on parents as they care for their children, and the challenges this presents for their research productivity, among other things. Thus, the primary concern garnered from these responses is the worry that the parent productivity gap in academia will be perpetuated by the pandemic.

In sum, our analyses provide an initial snapshot of the impact of the pandemic on scholars. More work is needed to better understand the perceived effect of the pandemic on scholarly productivity, including assessing the difference between self-reported and demonstrated declines in productivity. Though most of the higher education discussion has centered on students and health, there has been less has focus on the impact on faculty. More attention is warranted to the pandemic's fallout for faculty - whether childcare, mental health, job security, or otherwise. Sadly, as one of our respondents noted, even though each of us has 
faced a setback in some form due to the pandemic, the empathy necessary to carry us through to a kinder, more humane discipline may not materialize.

While our descriptive statistics appear to show the pandemic to be comprehensive and indiscriminate in its negative effects across faculty, it is also clear from both the descriptive statistics and the open-ended responses that further work is needed, particularly regarding the more vulnerable groups that faced structural inequalities prior to the COVID-19 pandemic. In considering policy solutions, higher education administrators should be mindful that the pandemic is not a cause of inequality but rather has served to enhance existing structural inequalities. 


\section{References}

APSA. 2020. "Data on the Profession.” https://www.apsanet.org/RESOURCES/Data-on-theProfession/Dashboards/P-WAM (accessed June 16, 2020).

Fattore, Christina. 2018. “Nevertheless, She Persisted: Women's Experiences and Perceptions within the International Studies Association.” International Studies Perspectives 20(1): 46-62.

Flaherty, Colleen. 2020. No Room of One's Own: Early Journal Submission Data Suggest COVID_19 is Taking Women's Research Productivity. Inside Higher Ed.

https://www.insidehighered.com/news/2020/04/21/early-journal-submission-data-suggest-covid19-tanking-womens-research-productivity (accessed June 30, 2020).

Hancock, Kathleen, Matthew Baum, and Marijke Breuning. 2013. "Women and Pre-Tenure Scholarly Productivity in International Studies: An Investigation into the Leaky Career Pipeline.” International Studies Perspectives 14 (4): 507-27.

Kitchener, Caroline. 2020. "Women Academics Seem to Be Submitting Fewer Papers during Coronavirus. 'Never Seen Anything like It,' Says One Editor.” https://www.thelily.com. https://www.thelily.com/women-academics-seem-to-be-submitting-fewer-papers-duringcoronavirus-never-seen-anything-like-it-says-one-editor// (accessed April 28, 2020). 
Malisch, Jessica L., Breanna N. Harris, Shanen M. Sherrer, Kristy A. Lewis, Stephanie L. Shepherd, Pumtiwitt C. McCarthy, Jessica L. Spott, Elizabeth P. Karam, Naima MoustaidMoussa, Jessica McCrory Calarco, Latha Ramalingam, Amelia E. Talley, Jaclyn E. CanasCarrell, Karin Ardon-Dryer, Dana A. Weiser, Ximena E. Bernal, and Jennifer Deitloff. 2020. "In the Wake of COVID-19, Academia Needs New Solutions to Ensure Gender Equity" PNAS www.pnas.org/cgi/doi/10.1073/pnas.2010636117 (accessed June 18, 2020).

Matthews, David. 2020. Pandemic Lockdown Holding Back Female Academics, Data Show. Times Higher Education https://www.timeshighereducation.com/news/pandemic-lockdownholding-back-female-academics-data-show (accessed June 26, 2020).

Miller, Claire Cain. 2020. "Nearly Half of Men Say They Do Most of the Home Schooling. 3 Percent of Women Agree.” New York Times https://www.nytimes.com/2020/05/06/upshot/pandemic-chores-homeschooling-gender.html (accessed May 6, 2020).

Minello, Alessandra. 2020. "The Pandemic and the Female Academic.” Nature. https://www.nature.com/articles/d41586-020-01135-9 (accessed April 28, 2020).

National Science Foundation, National Center for Science and Engineering Statistics (NCSES). 2019. Doctorate Recipients from US Universities: 2018. Arlington, VA (NSF 20-301).

Data tables available at https://ncses.nsf.gov/pubs/nsf20301/data-tables. (accessed June 15, 2020). 
Schiebinger, Londa, and Shannon K. Gilmartin. (2010) Housework Is an Academic Issue: How to Keep Talented Women Scientists in the Lab, Where They Belong. Academe 96(1): 39-44. Available at https://www.aaup.org/article/housework-academic-issue\#.XuhBned7k2w. (accessed June 15, 2020.

Stack, Steven. 2004. Gender, Children, and Research Productivity. Research in Higher Education 45(8): 891-920.

Viglione, Giuliana. Are Women Publishing Less During the Pandemic? Here's What the Data Say. Nature 581:365 -366.

Windsor, Leah, and Kerry Crawford. 2020a. "Snow Days, Holidays and Pandemic Quarantines: Why We Need to Be Looking after Parents." Medium. https://medium.com/international-affairsblog/snow-days-holidays-and-pandemic-quarantines-why-we-need-to-be-looking-after-parents-

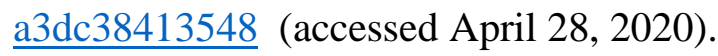

Windsor, Leah C., and Kerry F. Crawford. 2020b. Best Practices for Normalizing Parents in the Academy: Higher- and Lower-Order Processes and Women and Parents' Success. PS: Political Science and Politics 53(2):275-280. 
Table 1. Perceptions of Productivity and Parenting During and After the Pandemic

\begin{tabular}{|c|c|c|c|c|c|c|c|c|c|}
\hline & \multicolumn{3}{|c|}{ All Respondents } & \multicolumn{3}{|l|}{ Parents } & \multicolumn{3}{|c|}{ Single Parents } \\
\hline & $\mathrm{M}$ & $\mathrm{F}$ & Total & $\mathrm{M}$ & $\mathrm{F}$ & Total & $\mathrm{M}$ & $\mathrm{F}$ & Total \\
\hline \multicolumn{10}{|c|}{ Statement 1: I am unable to write/research at home in a way similar to my productivity prior to March 2020.} \\
\hline (Strongly) disagree & $21.2 \%$ & $21.2 \%$ & 181 & $21.1 \%$ & $22.3 \%$ & 73 & $0.0 \%$ & $17.4 \%$ & 4 \\
\hline Neither agree nor disagree & $11.3 \%$ & $11.1 \%$ & 95 & $8.6 \%$ & $11.2 \%$ & 34 & $14.3 \%$ & $0.0 \%$ & 1 \\
\hline (Strongly) agree & $67.5 \%$ & $67.7 \%$ & 576 & $70.3 \%$ & $66.5 \%$ & 227 & $85.7 \%$ & $82.6 \%$ & 25 \\
\hline \multirow[t]{2}{*}{$N$} & 292 & 560 & 852 & 128 & 206 & 334 & 7 & 23 & 30 \\
\hline & \multicolumn{3}{|c|}{$\chi=0.0104, \mathrm{p}=0.995$} & \multicolumn{3}{|c|}{$\chi=0.7364, p=0.692$} & \multicolumn{3}{|c|}{$\chi=4.5093, \mathrm{p}=0.105$} \\
\hline \multicolumn{10}{|c|}{ Statement 2: I worry that my research productivity will decrease significantly because of the COVID-19 pandemic } \\
\hline (Strongly) disagree & $17.6 \%$ & $17.0 \%$ & 147 & $15.9 \%$ & $16.2 \%$ & 53 & $0.0 \%$ & $21.7 \%$ & 5 \\
\hline Neither agree nor disagree & $13.1 \%$ & $14.2 \%$ & 118 & $11.9 \%$ & $13.2 \%$ & 42 & $42.9 \%$ & $8.7 \%$ & 5 \\
\hline (Strongly) agree & $69.3 \%$ & $68.8 \%$ & 589 & $72.2 \%$ & $70.6 \%$ & 235 & $57.1 \%$ & $69.6 \%$ & 20 \\
\hline \multirow[t]{2}{*}{$N$} & 290 & 564 & 854 & 126 & 204 & 330 & 7 & 23 & 30 \\
\hline & \multicolumn{3}{|c|}{$\chi=0.2049, \mathrm{p}=0.903$} & \multicolumn{3}{|c|}{$\chi=0.1420, p=0.931$} & \multicolumn{3}{|c|}{$\chi=5.4037, \mathrm{p}=0.067$} \\
\hline \multicolumn{10}{|c|}{ Statement 3: Post-pandemic, academia will be more considerate concerning the effects of caregiving on scholar productivity. } \\
\hline (Strongly) disagree & $49.0 \%$ & $50.3 \%$ & 427 & $50.8 \%$ & $52.7 \%$ & 172 & $42.9 \%$ & $58.3 \%$ & 17 \\
\hline Neither agree nor disagree & $24.3 \%$ & $26.2 \%$ & 219 & $21.8 \%$ & $25.1 \%$ & 79 & $42.9 \%$ & $16.7 \%$ & 7 \\
\hline (Strongly) agree & $26.7 \%$ & $23.5 \%$ & 211 & $27.4 \%$ & $22.2 \%$ & 80 & $14.3 \%$ & $25.0 \%$ & 7 \\
\hline \multirow[t]{2}{*}{$N$} & 288 & 569 & 857 & 124 & 207 & 331 & 7 & 24 & 31 \\
\hline & \multicolumn{3}{|c|}{$\chi=1.1184, p=0.572$} & \multicolumn{3}{|c|}{$\chi=1.2816, p=0.527$} & \multicolumn{3}{|c|}{$\chi=2.1585, \mathrm{p}=0.340$} \\
\hline \multicolumn{10}{|c|}{ Statement 4: Women will be worse off than men in academia, post-pandemic. } \\
\hline (Strongly) disagree & $5.8 \%$ & $8.4 \%$ & 65 & $7.0 \%$ & $6.8 \%$ & 23 & $14.3 \%$ & $0.0 \%$ & 1 \\
\hline Neither agree nor disagree & $17.1 \%$ & $16.1 \%$ & 142 & $17.2 \%$ & $18.4 \%$ & 60 & $14.3 \%$ & $13.0 \%$ & 4 \\
\hline (Strongly) agree & $77.1 \%$ & $75.5 \%$ & 655 & $75.8 \%$ & $74.8 \%$ & 251 & $71.4 \%$ & $87.0 \%$ & 25 \\
\hline \multirow[t]{2}{*}{$N$} & 292 & 570 & 862 & 128 & 206 & 334 & 7 & 23 & 30 \\
\hline & \multicolumn{3}{|c|}{$\chi=1.9094, p=0.385$} & \multicolumn{3}{|c|}{$\chi=0.0870, p=0.957$} & \multicolumn{3}{|c|}{$\chi=3.4472, p=0.178$} \\
\hline
\end{tabular}




\section{Appendix A. Additional Analyses, Full Sample}

Table 1. Perceptions of Productivity of Respondents with and without Parenting Roles

\begin{tabular}{|c|c|c|c|c|c|c|c|c|c|}
\hline & \multicolumn{3}{|c|}{ All Respondents } & \multicolumn{3}{|c|}{ Female Respondents } & \multicolumn{3}{|c|}{ Male Respondents } \\
\hline & Not Parent & Parent & Total & Not Parent & Parent & Total & Not Parent & Parent & Total \\
\hline \multicolumn{10}{|c|}{ Statement 1: I am unable to write/research at home in a way similar to my productivity prior to March 2020.} \\
\hline (Strongly) disagree & $20.7 \%$ & $21.9 \%$ & 181 & $20.7 \%$ & $22.3 \%$ & 119 & $21.0 \%$ & $21.1 \%$ & 61 \\
\hline Neither agree nor disagree & $11.9 \%$ & $10.2 \%$ & 96 & $11.0 \%$ & $11.2 \%$ & 62 & $13.6 \%$ & $8.6 \%$ & 33 \\
\hline (Strongly) agree & $67.4 \%$ & $68.0 \%$ & 578 & $68.3 \%$ & $66.5 \%$ & 378 & $65.4 \%$ & $70.3 \%$ & 196 \\
\hline$N$ & \multicolumn{3}{|c|}{$\chi=0.6693, p=0.716$} & \multicolumn{3}{|c|}{$\chi=0.2281, \mathrm{p}=0.892$} & \multicolumn{3}{|c|}{$\chi=1.8148, p=0.404$} \\
\hline
\end{tabular}

Statement 2: I worry that my research productivity will decrease significantly because of the COVID-19 pandemic

\begin{tabular}{|l|r|r|r|r|r|r|r|r|r|}
\hline (Strongly) disagree & $18.4 \%$ & $16.1 \%$ & 150 & $17.3 \%$ & $16.2 \%$ & 95 & $19.1 \%$ & $15.9 \%$ & 51 \\
\hline Neither agree nor disagree & $14.4 \%$ & $12.7 \%$ & 118 & $14.8 \%$ & $13.2 \%$ & 80 & $14.2 \%$ & $11.9 \%$ & 38 \\
\hline (Strongly) agree & $67.2 \%$ & $71.2 \%$ & 590 & $68.0 \%$ & $70.6 \%$ & 388 & $66.7 \%$ & $72.2 \%$ & 199 \\
\hline$N$ & 528 & 330 & 858 & 359 & 204 & 563 & 162 & 126 & 288 \\
\hline & $\chi$ & & &
\end{tabular}

Statement 3: Post-pandemic, academia will be more considerate concerning the effects of caregiving on scholar productivity.

\begin{tabular}{|c|c|c|c|c|c|c|c|c|c|}
\hline (Strongly) disagree & $48.4 \%$ & $52.0 \%$ & 429 & $48.7 \%$ & $52.7 \%$ & 285 & $48.2 \%$ & $50.8 \%$ & 141 \\
\hline Neither agree nor disagree & $26.7 \%$ & $23.9 \%$ & 221 & $26.9 \%$ & $25.1 \%$ & 149 & $25.3 \%$ & $21.8 \%$ & 68 \\
\hline (Strongly) agree & $24.9 \%$ & $24.2 \%$ & 212 & $24.4 \%$ & $22.2 \%$ & 134 & $26.5 \%$ & $27.4 \%$ & 77 \\
\hline$N$ & 531 & 331 & 862 & 361 & 207 & 568 & 162 & 124 & 286 \\
\hline
\end{tabular}

Statement 4: Women will be worse off than men in academia, post-pandemic.

\begin{tabular}{|c|c|c|c|c|c|c|c|c|c|}
\hline (Strongly) disagree & $7.9 \%$ & $6.9 \%$ & 65 & $9.4 \%$ & $6.8 \%$ & 48 & $4.9 \%$ & $7.0 \%$ & 17 \\
\hline Neither agree nor disagree & $15.8 \%$ & $18.0 \%$ & 144 & $14.9 \%$ & $18.5 \%$ & 92 & $17.3 \%$ & $17.2 \%$ & 50 \\
\hline$N$ & 533 & 334 & 867 & 363 & 206 & 569 & 162 & 128 & 290 \\
\hline
\end{tabular}


Table 2. Assistant Professors and Graduate Students' Perceptions of Productivity During and After the Pandemic

\begin{tabular}{|c|c|c|c|c|c|c|c|c|c|c|c|c|}
\hline & \multicolumn{3}{|c|}{ Assistant Professors } & \multicolumn{3}{|c|}{ Assistant Prof Parents } & \multicolumn{3}{|c|}{ Graduate Students } & \multicolumn{3}{|c|}{ Graduate Student Parents } \\
\hline & $\mathrm{M}$ & $\mathrm{F}$ & Total & $\mathrm{M}$ & $\mathrm{F}$ & Total & $\mathrm{M}$ & $\mathrm{F}$ & Total & $\mathrm{M}$ & $\mathrm{F}$ & Total \\
\hline \multicolumn{13}{|c|}{ Statement 1: I am unable to write/research at home in a way similar to my productivity prior to March 2020.} \\
\hline (Strongly) disagree & $22.1 \%$ & $19.8 \%$ & 43 & $23.1 \%$ & $16.9 \%$ & 19 & $28.2 \%$ & $19.6 \%$ & 39 & $40.0 \%$ & $38.5 \%$ & 7 \\
\hline Neither agree nor disagree & $9.1 \%$ & $8.4 \%$ & 18 & $7.7 \%$ & $6.8 \%$ & 7 & $15.4 \%$ & $11.2 \%$ & 22 & $0.0 \%$ & $15.4 \%$ & 2 \\
\hline (Strongly) agree & $68.8 \%$ & $71.8 \%$ & 147 & $69.2 \%$ & $76.3 \%$ & 72 & $56.4 \%$ & $69.2 \%$ & 121 & $60.0 \%$ & $46.1 \%$ & 9 \\
\hline \multirow[t]{2}{*}{ Total } & 77 & 131 & 208 & 39 & 59 & 98 & 39 & 143 & 182 & 5 & 13 & 18 \\
\hline & \multicolumn{3}{|c|}{$\chi=0.2024, p=0.904$} & \multicolumn{3}{|c|}{$\chi=0.6405, \mathrm{p}=0.726$} & \multicolumn{3}{|c|}{$\chi=2.2679, \mathrm{p}=0.322$} & \multicolumn{3}{|c|}{$\chi=0.9099, \mathrm{p}=0.634$} \\
\hline \multicolumn{13}{|c|}{ Statement 2: I worry that my research productivity will decrease significantly because of the COVID-19 pandemic } \\
\hline (Strongly) disagree & $18.7 \%$ & $16.0 \%$ & 35 & $23.7 \%$ & $12.1 \%$ & 16 & $27.5 \%$ & $15.5 \%$ & 33 & $20.0 \%$ & $33.3 \%$ & 5 \\
\hline Neither agree nor disagree & $9.3 \%$ & $15.3 \%$ & 27 & $10.5 \%$ & $15.5 \%$ & 13 & $17.5 \%$ & $14.1 \%$ & 27 & $20.0 \%$ & $0.0 \%$ & 1 \\
\hline (Strongly) agree & $72.0 \%$ & $68.7 \%$ & 144 & $65.8 \%$ & $72.4 \%$ & 67 & $55.0 \%$ & $70.4 \%$ & 122 & $60.0 \%$ & $66.7 \%$ & 11 \\
\hline \multirow[t]{2}{*}{ Total } & 75 & 131 & 206 & 38 & 58 & 96 & 40 & 142 & 182 & 5 & 12 & 17 \\
\hline & \multicolumn{3}{|c|}{$\chi=1.5505, \mathrm{p}=0.461$} & \multicolumn{3}{|c|}{$\chi=2.4251, \mathrm{p}=0.297$} & \multicolumn{3}{|c|}{$\chi=3.8343, \mathrm{p}=0.147$} & \multicolumn{3}{|c|}{$\chi=2.6376, \mathrm{p}=0.267$} \\
\hline \multicolumn{13}{|c|}{ Statement 3: Post-pandemic, academia will be more considerate concerning the effects of caregiving on scholar productivity. } \\
\hline (Strongly) disagree & $57.9 \%$ & $47.0 \%$ & 106 & $61.5 \%$ & $50.8 \%$ & 54 & $31.6 \%$ & $54.1 \%$ & 91 & $25.0 \%$ & $53.8 \%$ & 8 \\
\hline Neither agree nor disagree & $21.1 \%$ & $35.6 \%$ & 63 & $15.4 \%$ & $35.6 \%$ & 27 & $34.2 \%$ & $20.6 \%$ & 43 & $25.0 \%$ & $23.1 \%$ & 4 \\
\hline (Strongly) agree & $21.1 \%$ & $17.4 \%$ & 39 & $23.1 \%$ & $13.6 \%$ & 17 & $34.2 \%$ & $25.3 \%$ & 50 & $50.0 \%$ & $23.1 \%$ & 5 \\
\hline \multirow[t]{2}{*}{ Total } & 76 & 132 & 208 & 39 & 59 & 98 & 38 & 146 & 184 & 4 & 13 & 17 \\
\hline & \multicolumn{3}{|c|}{$\chi=4.8410, p=0.089$} & \multicolumn{3}{|c|}{$\chi=5.1935, \mathrm{p}=0.075$} & \multicolumn{3}{|c|}{$\chi=6.3759, p=0.041$} & \multicolumn{3}{|c|}{$\chi=1.2995, \mathrm{p}=0.522$} \\
\hline \multicolumn{13}{|c|}{ Statement 4: Women will be worse off than men in academia, post-pandemic. } \\
\hline (Strongly) disagree & $1.3 \%$ & $5.3 \%$ & 8 & $2.5 \%$ & $8.5 \%$ & 6 & $5.1 \%$ & $12.3 \%$ & 20 & $0.0 \%$ & $7.7 \%$ & 1 \\
\hline Neither agree nor disagree & $16.9 \%$ & $14.4 \%$ & 32 & $20.0 \%$ & $15.2 \%$ & 17 & $25.6 \%$ & $15.1 \%$ & 32 & $40.0 \%$ & $23.1 \%$ & 5 \\
\hline (Strongly) agree & $81.8 \%$ & $80.3 \%$ & 169 & $77.5 \%$ & $76.3 \%$ & 76 & $69.2 \%$ & $72.6 \%$ & 133 & $60.0 \%$ & $69.2 \%$ & 12 \\
\hline \multirow[t]{2}{*}{ Total } & 77 & 132 & 209 & 40 & 59 & 99 & 39 & 146 & 185 & 5 & 13 & 18 \\
\hline & \multicolumn{3}{|c|}{$\chi=2.2478, p=0.325$} & \multicolumn{3}{|c|}{$\chi=1.7214, p=0.423$} & \multicolumn{3}{|c|}{$\chi=3.5138, p=0.173$} & \multicolumn{3}{|c|}{$\chi=0.8031, p=0.669$} \\
\hline
\end{tabular}




\section{Appendix B. Respondents Residing in the US Only}

Table 1. Perceptions of Productivity and Parenting During and After the Pandemic - US Respondents

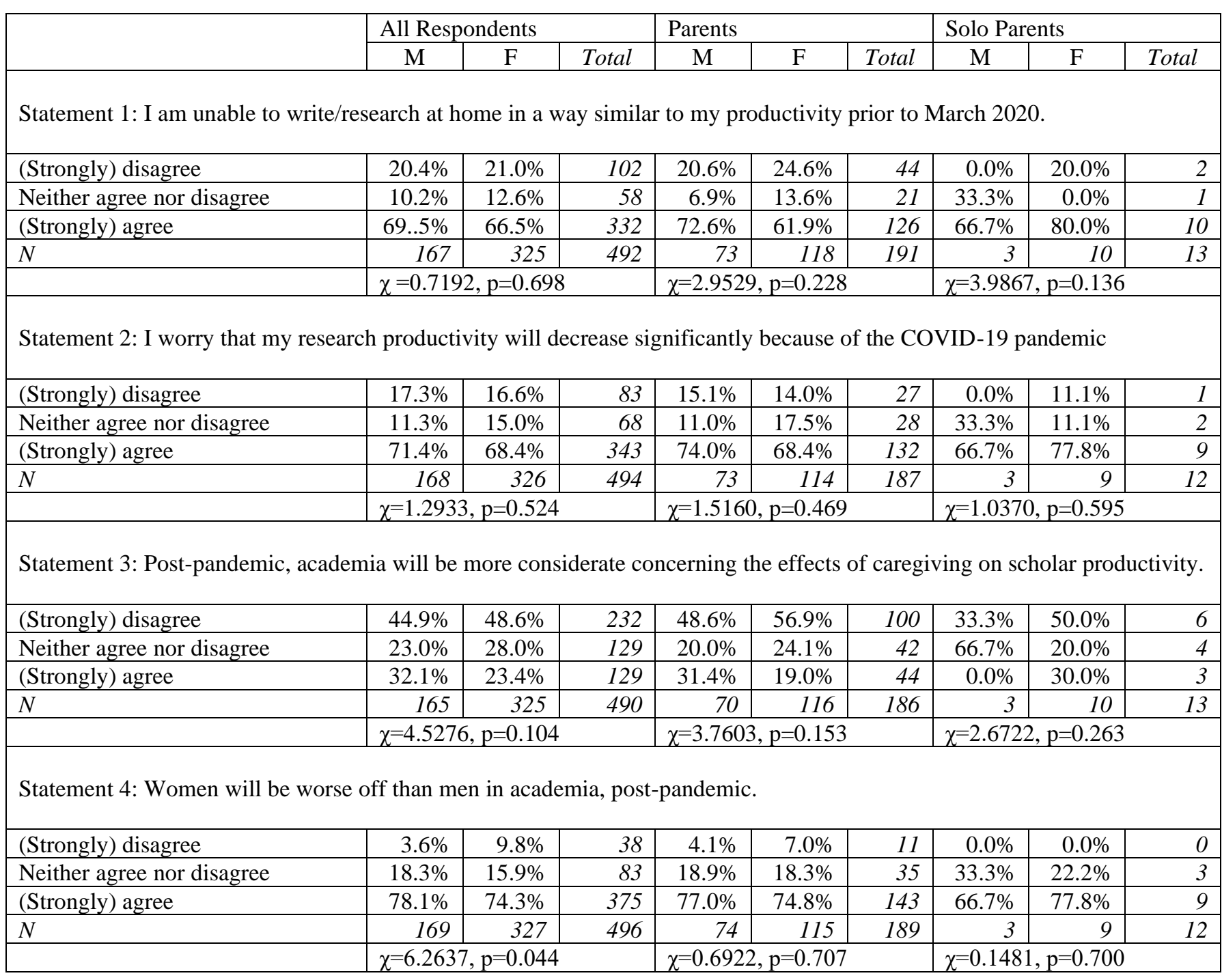


Table 2. Perceptions of Productivity of Respondents with and without Parenting Roles - US Respondents

\begin{tabular}{|c|c|c|c|c|c|c|c|c|c|}
\hline & \multicolumn{3}{|c|}{ All Respondents } & \multicolumn{3}{|c|}{ Female Respondents } & \multicolumn{3}{|c|}{ Male Respondents } \\
\hline & Not Parent & Parent & Total & Not Parent & Parent & Total & Not Parent & Parent & Total \\
\hline \multicolumn{10}{|c|}{ Statement 1: I am unable to write/research at home in a way similar to my productivity prior to March 2020.} \\
\hline (Strongly) disagree & $19.3 \%$ & $23.0 \%$ & 102 & $18.9 \%$ & $24.6 \%$ & 68 & $19.6 \%$ & $20.6 \%$ & 33 \\
\hline Neither agree nor disagree & $12.3 \%$ & $11.0 \%$ & 58 & $12.1 \%$ & $13.6 \%$ & 41 & $13.0 \%$ & $6.9 \%$ & 17 \\
\hline$N$ & \multicolumn{3}{|c|}{$\chi=1.0443, \mathrm{p}=0.593$} & \multicolumn{3}{|c|}{$\chi=1.8237, \mathrm{p}=0.402$} & \multicolumn{3}{|c|}{$\chi=1.6940, \mathrm{p}=0.429$} \\
\hline \multicolumn{10}{|c|}{ Statement 2: I worry that my research productivity will decrease significantly because of the COVID-19 pandemic } \\
\hline (Strongly) disagree & $18.3 \%$ & $14.4 \%$ & 83 & $17.5 \%$ & $14.0 \%$ & 56 & $19.6 \%$ & $20.6 \%$ & 33 \\
\hline Neither agree nor disagree & $13.1 \%$ & $15.0 \%$ & 68 & $13.7 \%$ & $17.5 \%$ & 49 & $13.0 \%$ & $6.9 \%$ & 17 \\
\hline \multicolumn{10}{|c|}{ Statement 3: Post-pandemic, academia will be more considerate concerning the effects of caregiving on scholar productivity. } \\
\hline (Strongly) disagree & $43.4 \%$ & $53.8 \%$ & 232 & $43.7 \%$ & $56.9 \%$ & 157 & $43.0 \%$ & $48.6 \%$ & 74 \\
\hline Neither agree nor disagree & $28.3 \%$ & $22.6 \%$ & 128 & $30.3 \%$ & $24.1 \%$ & 91 & $23.7 \%$ & $20.0 \%$ & 36 \\
\hline (Strongly) agree & $28.3 \%$ & $23.7 \%$ & 130 & $26.0 \%$ & $19.0 \%$ & 76 & $33.3 \%$ & $31.4 \%$ & 53 \\
\hline \multirow[t]{2}{*}{$N$} & 304 & 186 & 490 & 208 & 116 & 324 & 93 & 70 & 163 \\
\hline & \multicolumn{3}{|c|}{$\chi=4.9805, \mathrm{p}=0.083$} & \multicolumn{3}{|c|}{$\chi=5.2130, \mathrm{p}=0.074$} & \multicolumn{3}{|c|}{$\chi=0.5583, \mathrm{p}=0.756$} \\
\hline \multicolumn{10}{|c|}{ Statement 4: Women will be worse off than men in academia, post-pandemic. } \\
\hline
\end{tabular}


Table 2. Assistant Professors and Graduate Students' Perceptions of Productivity During and After the Pandemic - US Respondents

\begin{tabular}{|c|c|c|c|c|c|c|c|c|c|c|c|c|}
\hline & \multicolumn{3}{|c|}{ Assistant Professors } & \multicolumn{3}{|c|}{ Assistant Prof Parents } & \multicolumn{3}{|c|}{ Graduate Students } & \multicolumn{3}{|c|}{ Graduate Student Parents } \\
\hline & $\mathrm{M}$ & $\mathrm{F}$ & Total & $\mathrm{M}$ & $\mathrm{F}$ & Total & $\mathrm{M}$ & $\mathrm{F}$ & Total & $\mathrm{M}$ & $\mathrm{F}$ & Total \\
\hline \multicolumn{13}{|c|}{ Statement 1: I am unable to write/research at home in a way similar to my productivity prior to March 2020.} \\
\hline (Strongly) disagree & $17.5 \%$ & $18.4 \%$ & 21 & $20.0 \%$ & $17.0 \%$ & 12 & $20.8 \%$ & $20.7 \%$ & 23 & $50.0 \%$ & $57.1 \%$ & 5 \\
\hline Neither agree nor disagree & $2.5 \%$ & $11.8 \%$ & 10 & $4.0 \%$ & $9.8 \%$ & 5 & $20.8 \%$ & $11.5 \%$ & 15 & $0.0 \%$ & $14.3 \%$ & 1 \\
\hline (Strongly) agree & $80.0 \%$ & $69.7 \%$ & 85 & $76.0 \%$ & $73.2 \%$ & 49 & $58.3 \%$ & $67.8 \%$ & 73 & $50.0 \%$ & $28.6 \%$ & 3 \\
\hline \multirow[t]{2}{*}{ Total } & 40 & 76 & 116 & 25 & 41 & 66 & 24 & 87 & 111 & 2 & 7 & 9 \\
\hline & \multicolumn{3}{|c|}{$\chi=3.0422, p=0.218$} & \multicolumn{3}{|c|}{$\chi=0.7691, p=0.681$} & \multicolumn{3}{|c|}{$\chi=1.4715, p=0.479$} & \multicolumn{3}{|c|}{$\chi=0.5143, p=0.773$} \\
\hline \multicolumn{13}{|c|}{ Statement 2: I worry that my research productivity will decrease significantly because of the COVID-19 pandemic } \\
\hline (Strongly) disagree & $17.1 \%$ & $18.4 \%$ & 21 & $23.1 \%$ & $12.5 \%$ & 11 & $20.0 \%$ & $12.6 \%$ & 16 & $0.0 \%$ & $33.3 \%$ & 2 \\
\hline Neither agree nor disagree & $2.4 \%$ & $14.5 \%$ & 12 & $3.8 \%$ & $15.0 \%$ & 7 & $20.0 \%$ & $16.1 \%$ & 19 & $50.0 \%$ & $0.0 \%$ & 1 \\
\hline (Strongly) agree & $80.5 \%$ & $67.1 \%$ & 84 & $73.1 \%$ & $72.5 \%$ & 48 & $60.0 \%$ & $71.3 \%$ & 77 & $50.0 \%$ & $66.7 \%$ & 5 \\
\hline \multirow{2}{*}{ Total } & 41 & 76 & 117 & 26 & 40 & 66 & 25 & 87 & 112 & 2 & 6 & 8 \\
\hline & \multicolumn{3}{|c|}{$\chi=4.4521, p=0.108$} & \multicolumn{3}{|c|}{$\chi=2.9068, p=0.234$} & \multicolumn{3}{|c|}{$\chi=1.2689, \mathrm{p}=0.530$} & \multicolumn{3}{|c|}{$\chi=3.7333, p=0.155$} \\
\hline \multicolumn{13}{|c|}{ Statement 3: Post-pandemic, academia will be more considerate concerning the effects of caregiving on scholar productivity. } \\
\hline (Strongly) disagree & $53.8 \%$ & $44.7 \%$ & 55 & $52.0 \%$ & $48.8 \%$ & 33 & $29.2 \%$ & $49.4 \%$ & 51 & $100.0 \%$ & $57.1 \%$ & 5 \\
\hline Neither agree nor disagree & $23.1 \%$ & $38.2 \%$ & 38 & $20.0 \%$ & $36.6 \%$ & 20 & $33.3 \%$ & $23.6 \%$ & 29 & $0.0 \%$ & $14.3 \%$ & 1 \\
\hline (Strongly) agree & $23.1 \%$ & $17.1 \%$ & 22 & $28.0 \%$ & $14.6 \%$ & 13 & $37.5 \%$ & $27.0 \%$ & 33 & $0.0 \%$ & $28.6 \%$ & 2 \\
\hline \multirow[t]{2}{*}{ Total } & 39 & 76 & 115 & 25 & 41 & 66 & 24 & 89 & 113 & 1 & 7 & 8 \\
\hline & \multicolumn{3}{|c|}{$\chi=2.7016, p=0.259$} & \multicolumn{3}{|c|}{$\chi=2.8505, p=0.240$} & \multicolumn{3}{|c|}{$\chi=3.1377, p=0.208$} & \multicolumn{3}{|c|}{$\chi=0.6857, p=0.710$} \\
\hline \multicolumn{13}{|c|}{ Statement 4: Women will be worse off than men in academia, post-pandemic. } \\
\hline (Strongly) disagree & $0.0 \%$ & $3.9 \%$ & 3 & $0.0 \%$ & $7.3 \%$ & 3 & $4.0 \%$ & $15.7 \%$ & 15 & $0.0 \%$ & $14.3 \%$ & 1 \\
\hline Neither agree nor disagree & $15.0 \%$ & $16.9 \%$ & 19 & $23.1 \%$ & $19.5 \%$ & 14 & $24.0 \%$ & $12.4 \%$ & 17 & $0.0 \%$ & $0.0 \%$ & 0 \\
\hline (Strongly) agree & $85.0 \%$ & $79.2 \%$ & 95 & $76.9 \%$ & $73.2 \%$ & 50 & $72.0 \%$ & $71.9 \%$ & 82 & $100.0 \%$ & $85.7 \%$ & 8 \\
\hline \multirow[t]{2}{*}{ Total } & 40 & 77 & 117 & 26 & 41 & 67 & 25 & 89 & 114 & 2 & 7 & 9 \\
\hline & \multicolumn{3}{|c|}{$\chi=1.7242, p=0.422$} & \multicolumn{3}{|c|}{$\chi=2.0292, p=0.363$} & \multicolumn{3}{|c|}{$\chi=3.8146, p=0.148$} & \multicolumn{3}{|c|}{$\chi=0.3214, p=0.571$} \\
\hline
\end{tabular}

